\title{
Bibliotherapy as an Alternative Approach to Children's Emotional Disorders
}

\author{
Ajayi Nathaniel Akinola \\ Hezekiah Oluwasanmi Library, Obafemi Awolowo University, Ile-Ife, Nigeria \\ Email: nathajayi@yahoo.co.uk \\ Received 22 May 2014; revised 27 June 2014; accepted 10 July 2014 \\ Copyright (C) 2014 by author and Scientific Research Publishing Inc. \\ This work is licensed under the Creative Commons Attribution International License (CC BY). \\ http://creativecommons.org/licenses/by/4.0/

(c) (i) Open Access

\begin{abstract}
The alternative approach to solving children emotional and behavioral disorders is the use of bibliotherapy. Many African youths today are undergoing traumatic democratic governance, fear of future and a crazy for materialism and books can be used to address the menace. The objectives of this paper therefore are to find out why and how bibliotherapy can be administered as a correctional therapy for children undergoing emotional and behavioral disorders. Good book selection, individual guidance and skilled therapist increase intellectual soundness of children.
\end{abstract}

\section{Keywords}

Bibliotherapy, Behavioral Disorders, Youth, Good Books, Correctional Therapy and Emotional Disorders

\section{Introduction}

Bibliotheraphy is the process of using books to help children think about, understand, and work through social and emotional concerns. Reading can be therapeutic because children enter the world described in the pages of a good book and become involved with the character there in having gained insight and ideas. Bibliotherapy assists youngster in overcoming the emotional turmoil related to real-life problem by having them read literature on that topic. Children identify with a book character and events on the story, either real or fictitious. Rozalski (2010) describes bibliotherapy as a projective indirect tool that employs literature for growth of children that can be used to teach children on life's challenges by encouraging them to connect with book characters, thereby letting readers evaluate their individual.

The goal of bibliotherapy is to broaden and deepen the children' understanding of a particular problem that requires attention. The written books may educate the children about their problem itself or be used to increase their acceptance of a proposed treatment. 
Opportunity to read about emotional and behavioral disorder outside the therapist's office facilitates active participation in the rehabilitation process and promotes a strong recovery.

Books have been instruments of change, development and effective decision-making since the time immemorial. No wonder, books have continued to be relevant from one generation to another. According to Ajayi (1997), Clarke, Lynch, \& Debar (2006) the use of books in the treatment of mentally sick people was dated back to $300 \mathrm{BC}$ when Aristotle delineated the influence that book had on the psyche, especially the purifying or purgative effect on tragedy. One of the earliest records of the use of bibliotherapy in the broadest sense namely "The use of books in treatment of the Sick" appeared in the Middle Ages in the thirteenth century. The AlMansur Hospital, then newly built in Cairo, provided along with medical and surgical care, the services of Priests to read Koran to patients day and night. In the $18^{\text {th }}$ and $19^{\text {th }}$ centuries, this was extensively practised in England, France, Germany and Scotland. The combination of religion and use of books (bibliotherapy) informed the beginning of hospital libraries.

\section{Justification for This Paper}

African children/youngsters are passing through traumatic democratic governance, fear of future and materialism. Cases of children truancy, disobedience, substance abuse, high crime rates, armed robberies, and other antisocial behaviors among youths are vast on the increase. Visit to mentally sick and remand homes, drug rehabilitation units, etc. shows a progressive increase in the involvement of the youths in crimes.

Children misbehave a time, but behavior disorders go beyond mischief and rebellion. African children because of the environmental factors that surround them not only misbehave but also deeply involved in many of these unwholesome behaviors. Children engaged in damaging and destroying public and private property, this act is very common among school children even tertiary institutions. Lying and stealing and deceitfulness-lies to obtain goods or favor or to avoid obligations breaking into houses, building or even cars. Skipping school culminates to not doing well in school. Many African youths today result to early smoking, drinking, drug use, early sexual activity and consistent hostility towards authority. Some used weapons that could cause serious physical harm to others. All these lead to conduct disorders in the society.

Books provide a safe medium for children to explore different concepts, feelings, and attitude while allowing them to better understand their environment, community, and societal expectation (Goddard, 2011). Reading increases self-esteem, gives comfort, and may aid children in coping with difficult situations. Bibliotherapy can be used to open communication between children, parents and teachers.

The objectives of this paper therefore are to find why and how use of bibliotherapy can be used as an alternative approach for children emotional disorder.

\section{Hypothetical Questions}

Why are youngsters having problem to adjusting in the relative world?

How can bibliotherapy help them to cope with reality of life?

There are several factors responsible for emotional and behavioral disorder in children. Bullying and teasing can cause emotional imbalance which if not attended to can lead to psychosocial disorders. No wonder Gregory and Vessey (2004) recommend the use of bibliotherapy to address childhood and bullying to promote healthy school environment because book serves as a unique conduit of exchange between parents, teachers and the children. Researchers in the field of Psychiatry have found the effectiveness and maintained the use of books for management of psychosocial disorders. Okoro and Azubogu (2007) for instance asserts that exposure to book medium is crucial to the large-scale psychosocial change and economic development in developing societies.

There are two approaches to the proper use of bibliotherapy. Firstly it should not be used without a skilled, especially trained bibliotherapist and secondly parent go, buy his kid children's book on the subject of interest, apply common sense and read to their child.

This second thought is a common practice because it takes special skills to be able to select and apply appropriately what kinds of books are good for a particular condition. The book therapist needs to analysize and understand the reader's needs and supply the needed book to him. Hence he is able to discover, and then reserve the thought that caused the depressive feeling of hopelessness, by giving the individual information materials that can help overcome the situation.

Bibliotherapy can be conducted either with individuals or in groups. In case of individual, bibliotherapy is 
able to unblock emotions and relieve emotional pressures. He is able to examine and analysize moral values thereby stimulate critical thinking, developing self awareness, enhancing self concept and improving personal and social judgment. With groups, youngsters become aware that they are not alone in their feelings and that perceived problems are shared by others.

Although childhood is generally regarded as a carefree time of life, many children and adolescents experience emotional difficulties growing up their behaviors on a continuum, and there is no specific line that separates troubling behavior from a serious emotional problem. Rather, a problem can range from mild to serious. Hence bibliotherapy is an instrument of a life change, development and effective decision-making. For the sake of this paper, three major human mind sets were discussed.

1) It is for the purpose of rebuilding thought structure. As the natural mind functions with a long-standing pattern of egocentric thoughts and desires, which, in turn produce all kinds of conflicts, the human mind, if it is to be renewed, must be able to think God's thought after him. This can be achieved by memorizing and meditating upon important passages in the books read. It is important that children of queried or immoral and maladaptive behavior are carefully and effectively moulded or corrected through the provision of good books.

2) It is to refocus children's emotions. Green (2008) argues that many kids suffer from a short attention span hence reading books will refocus their attention because there is nothing more relaxing than sitting outside in the garden with a good book to read, whilst the screen of the computer is bright and makes it hard to relax. Sridhar (2000) opines that bibliotherapy improves reading comprehension, enhances self-esteem and improves behavior of children.

3) It is to redirect will. The human will, apart from the action directed by good thought, is bent on having its own way. Books can be an alternative approach to solving human problems where information constitutes the raw material from which options or alternatives emerged. This means that alternatives to human problems can be retrieved through the supply of relevant information resources which are in the libraries. Ills among the young children like truancy, drug addiction and substances abuse, crimes and robberies can be corrected by bibliotherapy because it supports and reinforces individual and group counseling. Leininger (2010) discusses bibliotherapy as helping students gain insight into themselves while promoting problem-solving skills.

Bibliotherapy may be undertaken for many reasons because what we believe/read directly influences our performance and how we behave. So if a large variety of conflicting truths about live fill the minds of youngsters, it is no wonder that unrest, trouble and strife plagued the societies we live in today. The following are some of the reasons why bibliotherapy can be applied. It is used to develop an individual's self concept, to increase children's understanding of human behavior. Bibliotherapy provides a way for a kid to find interests outside of self and to relieve emotional or mental pressure. Reading of books can show a kid that he is not the first or only person to encounter such a problem and it teaches youth that there is more than one solution to a problem. It also helps kids discuss their problems freely, it assists an individual plan a constructive cause of action to solve a problem which might remain permanent. Studies have shown that African children only read to pass examinations therefore, introducing bibliotherapy would imbibe the culture of reading in them

Children become emotionally involved in the story he reads and is able to ease emotions when he is given the right conditions. This is better managed by those who possess these traits -personal stability, genuine interest in working with youngsters, and ability to emphathize with others without moralizing, intimidating or commanding.

In as much as administration of bibliotherapy is a sole responsibility of a skilled therapist, children must also be jealously guided by motivating them with introductory activities i.e. letting them know why they should read. Time must be provided for reading and allowing incubation/digestion period. Therapist must provide follow-up discussion time, using questions that will lead persons from literal call of information through interpretation, analysis, synthesis and evaluation of that information.

The therapist needs to identify the student and match him with appropriate material i.e. the book must be at the kid reading ability level. He must decide on setting time or seasons, design follow-up activities for the reading such as paper writing, drawing and drama. Kids must be allowed a few minutes to reflect on the material read.

The use of bibliotherapy cannot be effective without taken these precautions. Therapist must avoid topics (abortion, drug use, crime) which might draw concerns from parents, community, etc and must be familiar with the book by reading it and understand it before using it. 


\section{Implication for Teaching Practice}

Implications of bibliotherapy for teaching practice cannot be over-emphasized, teachers must see bibliotherapy as an innovative approach that they can use to help children deal with their problems. They should use literature to enhance induction, school efforts to mainstream special students, promotion of attitudes of respect and acceptance. According to Heath (2011), bibliotherapy helps to prevent bulling in schools through supporting classrooms in modeling and promotion of intended social interactions. Lok (2009) discusses the positive influence picture books can have when preparing a regular primary classroom for the arrival of a student with challenges. Elementary school teachers should construct and use interactive workbooks as a therapeutic strategy. Schumacher (1995) opines that bibliotherapy is an aid for elementary school counselors and psychologists because it guides in developing interactive workbooks.

Bibliotherapy, the process of reading books with therapeutic intent, must be seen as an effective means to implement character education within the curriculum. Stories can create an emotional attachment to goodness, a desire to do the right thing, provide a wealth of good examples - the kind of which are missing from a child's day-to-day environments, familiarize youngsters with the codes of conduct they need to know and help to make sense of life. Moreover, Hanley-Hochdorfer (2010) ascertains that one of the most popular treatment to address autism spectrum disorders is the use of social stories which is also beneficial at reducing many disruptive behaviors.

\section{Conclusion}

Bibliotherapy is referred to by Quzts and Palombo (2005) as a healing of the soul. It is an effective technique which can be used to help children, teenagers, and adult cope with their problems thus promoting mental health. Bibliotherapy offers solution to certain problems and breaks many attitudinal barriers to learning. While reading about a situation has the potential to sharpen perception and deepen understanding thereby increases intellectual soundness of children.

\section{Recommendation}

It is a widely accepted fact that African children don't read, they only read to pass examinations. Several studies have shown these Nneji (2002), Olaosebikan (2005), Obi (2006).

The following recommendations are made:

Parents as a matter of duty should introduce their children to reading.

Government should employ skilled bibliotherapist in the schools who will be in-charge of the school library books and prescribe and administer book therapy to children. Professional bodies such as Library Associations should promote reading culture in schools, organize exhibitions of children books, and write and publish children books.

Finally, the formula for emotional disorders is a good book selection and individual guidance of a definite goal equal to therapy.

\section{References}

Ajayi, N. A. (1997). Bibliotherapy in Health Care Delivery in Nigeria. Journal of Physical Education and Research, 3, 442-446.

Clarke, G., Lynch, F., Spofford, M., \& DeBar, L. (2006). Trends Influencing Future Delivery of Mental Health Services in Large Health Care Systems. Clinical Psychology: Science and Practice, 13, 287-292.

http://dx.doi.org/10.1111/j.1468-2850.2006.00040.x

Goddard, A. T. (2011). Children’s Books for Use in Bibliotherapy. Journal of Pediatric Health Care, 25, 57-61.

Green, J. (2008). The Effect of the Internet on Reading Habits. http://www.helum.con/items/1038985

Gregory, K. E., \& Vessey, J. A. (2004). Bibliotherapy: A Strategy to Help Students with Bulling. The Journal of School Nursing, 20, 127-133.

Hanley-Hochdorfer, K., Bray, M. A., Kehle, T. J., \& Elinoff, M. J. (2010). Social Stories to Increase Verbal Initiation in Children with Cultism and Asperger's Disorder. School Psychology Review, 39, 84.

Heath, M. A., Moulton, E., Dyches, T. T., Prater, M. A., \& Brown, A. (2011). Strengthening Elementary School Bully Prevention with Bibliotherapy. Communique, 39, 12. 
Leininger, M., Dyches, T. T., Prater, M. A., Health, M. A., \& Bascom, S. (2010). Books Portraying Characters with Obsessive-Compulsive Disorder. Teaching Exceptional Children, 42, 22.

Lok, C. (2009). Book Therapy: Power of Picture Books for an Inclusive Classroom. California Reader, $42,24$.

Nneji, L. (2014). Promoting Effective Study Habits in Nigerian University Students. http://www.eds.uwa.edu.au/iced/2002

Obi, F. A. (2005). We Do a Lot of Reading in Nigeria. http://news.bbc.co.uk. /2/hi/Africa /4365959.stm

Okoro, C. C., \& Azubogu, N. A. (2007). Bibliotherapy: A Tool for Improving Reading Culture among Nigeria Children. Information Technologist, 41, 81-88.

Olaosebiakan, B. (2005). Are Africans Reading? http://new.bbc.co.uk/2/hi/africa/4365958.stm

Quzts, D. T., \& Palombo, M. J. (2005). Bibliotherapy and Reading. Newsletter of the Special Interest Group of the International Reading Association. 15, 1-9.

Rozalski, M., Stewart, A., \& Miller, J. (2010). Bibliotherapy: Helping Children Cope with Life’s Challenges. Record, 47, 33.

Schumacher, R. B., \& Want, R. A. (1995). Elementary School Guidance \& Counseling. 29, 303.

Sridhar, D., \& Vaughn, S. (2000). Bibliotherapy for All. Teaching Exceptional Children, 33, 74. 
Scientific Research Publishing (SCIRP) is one of the largest Open Access journal publishers. It is currently publishing more than 200 open access, online, peer-reviewed journals covering a wide range of academic disciplines. SCIRP serves the worldwide academic communities and contributes to the progress and application of science with its publication.

Other selected journals from SCIRP are listed as below. Submit your manuscript to us via either submit@scirp.org or Online Submission Portal.
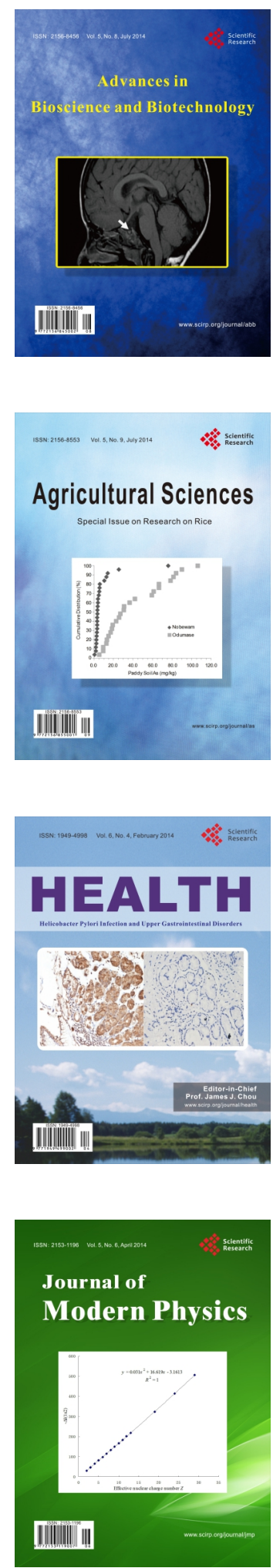
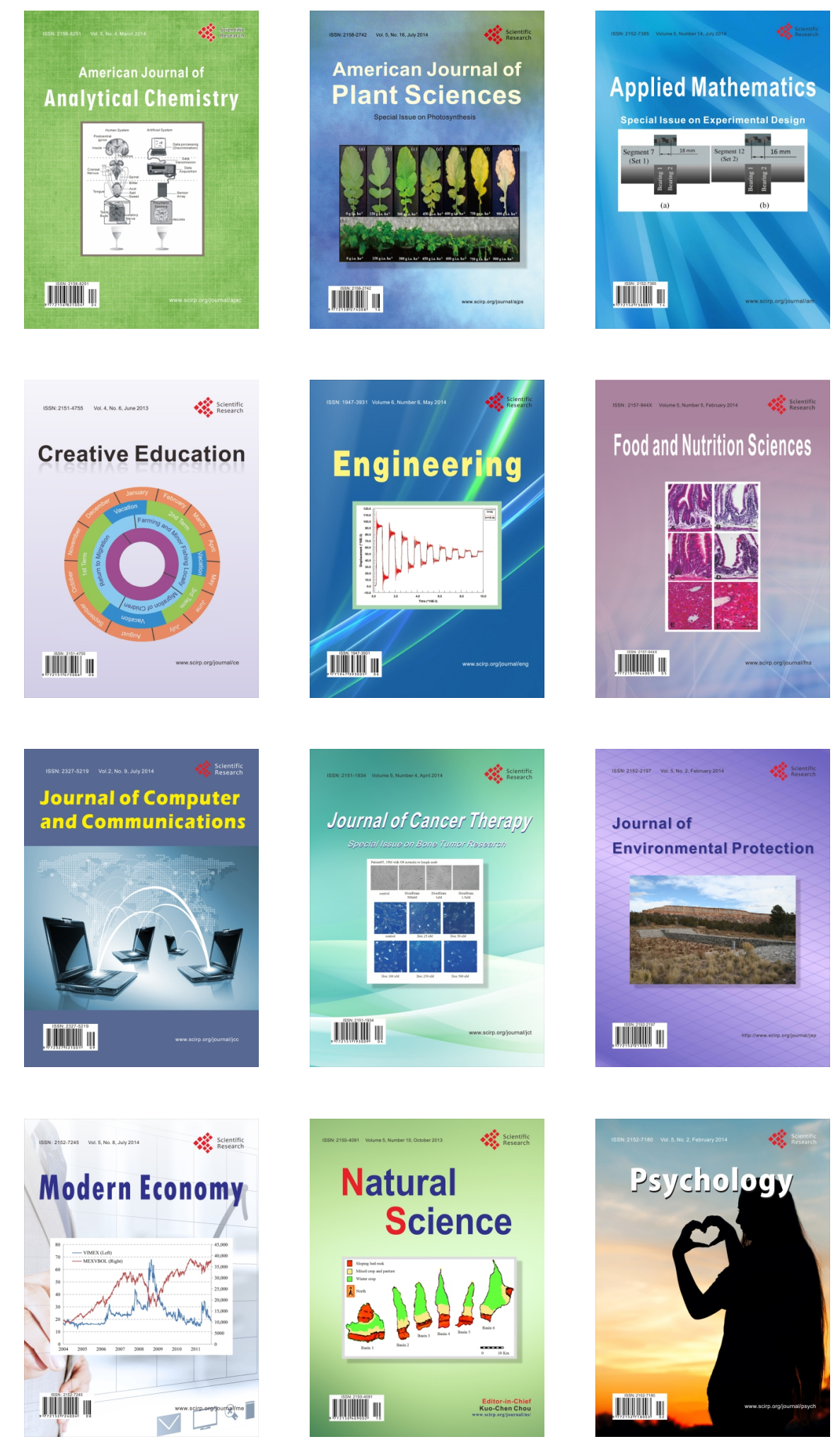